\title{
Dynamic Simulation Studies of Control Design for Engine Bleed Air Test Facility
}

\author{
Zheng Dai ${ }^{1}$, Yi Cui ${ }^{1}$ \\ ${ }^{1}$ Shanghai Aircraft Design and Research Institute, Commercial Aircraft Corporation of China Ltd, Shanghai, China
}

\begin{abstract}
This paper describes a model-based method for the control design of engine bleed air test facility for the bleed air system. In order to perform the control design, a dynamic simulation model for the facility is developed to simulate the dynamic behaviour. The main equipment dynamic modelling approaches are described. This simplified dynamic model may be used to perform trade studies and to optimize component characteristics for performance and cost comparison purposes. With the performance shown, this engine bleed air test facility should be quite capable to emulate the engine for bleed air system testing and evaluation.
\end{abstract}

\section{Introduction}

The environmental control system (ECS) of commercial aircraft contains several main subsystems as shown in figure 1 . The atmospheric environment within the flight envelope of the commercial aircraft varies drastically. For instance, the ambient temperature varies from $-55^{\circ} \mathrm{C}$ to $40^{\circ} \mathrm{C}$, the pressure varies from $20 \mathrm{kPa}$ to $101 \mathrm{kPa}$. The environmental control system is designed to control and regulate the interior environment of the aircraft cabin. The bleed air system is a highly coupled control system which regulates temperature and pressure of compressed engine bleed air and serves as the pneumatic air source for the downstream ECS subsystems.

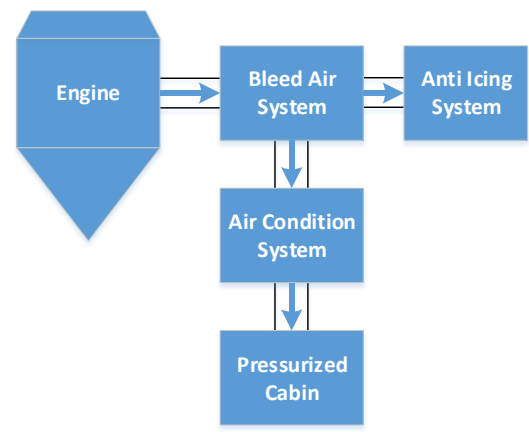

Figure 1. Simplified commercial aircraft ECS block diagram

The excellent dynamic performance of the bleed air system is the guarantee for the normal operation of the environmental control system. Poor dynamic characteristics may cause uncontrollability of the system. The parameters may oscillate with serious overshoot, causing a system alarm[1].

The Engine Bleed Air Test Facility (EBATF) is an essential infrastructure for the performance and verification test of the bleed air system. The objective of
EBATF is to provide airflow to simulate engine bleed air for bleed air system test bench[2-3]. The engine bleed air pressure and temperature can change rapidly, the pressure and temperature controlled by EBATF are therefore necessarily fast responding.

As shown in Figure 2, the general system architecture contains the main equipment:

- Compressed air source: to provide high pressure air;

- Heater: to heat the air for desired temperature;

- Heat exchanger: to cool the air;

- Control valve 1,2: to perform temperature control;

- Outflow valve 1,2: to perform pressure control.

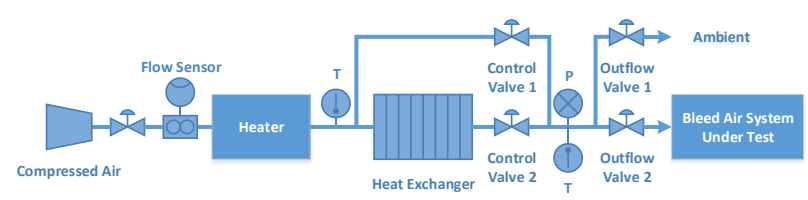

Figure 2. Simplified EBATF architecture diagram

In this paper a dynamic model of the EBATF is developed for the control design based on the fundamental of mechanics and heat transfer. And numerical simulation study is performed using the model. Several different control design methods are used and studied to realize the facility and meet the control requirements.

\section{Dynamic Requirements of The Facility}

The dynamic performance test of the bleed air system requires that the air temperature and pressure at the inlet of the pipeline can be rapidly changed. Therefore, the control system must overcome the inherent thermal inertia, volume inertia, and coupling characteristics between the control parameters. For ECS applications, 
engine bleed air pressure and temperature from the engine high pressure port typically range from 40 psia to 500 psia and $230{ }^{\circ} \mathrm{C}$ to $650{ }^{\circ} \mathrm{C}$. During takeoff, the pressure and temperature could change from 55 psia to 550 psia and $260{ }^{\circ} \mathrm{C}$ to $650{ }^{\circ} \mathrm{C}$ rapidly. During cruise at $40000 \mathrm{ft}$, the pressure and temperature are around 160 psia and $550{ }^{\circ} \mathrm{C}$. At the same altitude for descend, they are about 50 psia and $360{ }^{\circ} \mathrm{C}$. For the low pressure port, engine bleed air pressure and temperature typically range from 10 to 150 psia and $95{ }^{\circ} \mathrm{C}$ to $375^{\circ} \mathrm{C}$. During takeoff, the pressure and temperature could change from 10 psia to 150 psia and $45^{\circ} \mathrm{C}$ to $355^{\circ} \mathrm{C}$ rapidly. During cruise at $40000 \mathrm{ft}$, the pressure and temperature are around $35 \mathrm{psia}$ and $280{ }^{\circ} \mathrm{C}$. At the same altitude for descend, they are about 10 psia and $130{ }^{\circ} \mathrm{C}$.

However, during rapid engine pressure transient like take off operation, both pressure and temperature can change rapidly and form one operation state to another operation state in about 5 to 10 seconds. Hence, it would be necessary for the EBATF to emulate this rapid pressure and transient performance on ground.

Despite the difficulty, the ideal dynamic performance of the EBATF is described in detail as follows:

- Maximum temperature change :

- Rise from $260{ }^{\circ} \mathrm{C}$ to $600{ }^{\circ} \mathrm{C}$ in $10 \mathrm{sec}$

Drop from $650{ }^{\circ} \mathrm{C}$ to $300{ }^{\circ} \mathrm{C}$ in $10 \mathrm{sec}$

- Maximum pressure change :

- Rises from 100 psia to 500 psia within $5 \mathrm{sec}$

- Drop from 450 psia to 50 psia within $5 \mathrm{sec}$

In order to meet these requirements, a preliminary dynamic simulation model for EBATF is developped according to the general system architecture. Common equipment performance is chosen to reflect the real system state to the greatest extent. The temperature and pressure control design will be studied based on this model to make a preliminary assessment about the dynamic control performance.

\section{Modelling Approach}

\subsection{Heater model}

The heater is represented by a simple nonlinear model based on energy balance approach with a time constant at maximum flow rates to simulate warm up time at full airflow rate.

The heater is modeled by equation (1).

$$
M_{h} C_{h}\left(d T_{o} / d t\right)=W C_{p}\left(T_{o}-T_{i}\right)+Q
$$

Where $M_{h} C_{h}$ is the thermal mass of the heater, $W$ is the airflow rate through the heater, $T_{i}$ is the inlet air temperature, $C_{p}$ is the specific heat of air and $Q$ is the heating power. The model assumes perfect heat transfer between the electrical heating element and airflow with no energy losses.

\subsection{Valve Model}

All the valves are butterfly type with specific leakage area. The flow of the valve is calculated based on the inlet and outlet pressure, temperature, and the opening of the valve. The calculation expression is as shown in equation (2)[4-6] below.

$$
W=K A \frac{p_{i}}{\sqrt{T_{i}}} \phi(\varsigma)
$$

Where $\zeta=p_{o} / p_{i}, \phi(\varsigma)$ can be calculated by equation (3) and (4). $K$ is flow coefficient, $A$ is flow area, $p_{i}, T_{\mathrm{i}}$ are valve inlet air pressure and temperature, $p_{o}$ is valve outlet air pressure.

$$
\begin{gathered}
\phi(\varsigma)=\left(\varsigma^{\frac{2}{\kappa}}-\varsigma^{\frac{\kappa+1}{\kappa}}\right)^{0.5}\left[\frac{2 \kappa}{R(\kappa-1)}\right]^{0.5}, \varsigma>0.528 \\
\phi(\varsigma)=\left(\frac{2}{\kappa+1}\right)^{\frac{\kappa}{\kappa-1}}\left[\frac{2 \kappa}{R(\kappa-1)}\right]^{0.5}, \varsigma \leq 0.528 \\
\text { Valve Command }
\end{gathered}
$$

Figure 3. Valve model block diagram

The valve actuation dynamics will be represented by using a first order transfer function with a time constant. And a simple backlash function block is also used as shown in figure 3 .

\subsection{Air Duct Model}

The air ducts are assumed to be made of stainless steel and modeled by equation (5), (6), (7), (8). The pressure loss of air flow in the duct is calculated according to equation (9)

$$
\begin{gathered}
M_{m} C_{m}\left(d T_{m} / d t\right)=Q_{f}+Q_{a} \\
Q_{f}=W_{f} C_{f}\left(1-\exp \left(-H_{f} / W_{f} C_{f}\right)\right)\left(T_{i}-T_{m}\right) \\
Q_{a}=H_{a}\left(T_{a}-T_{m}\right) \\
T_{o}=T_{m}+\left(T_{i}-T_{m}\right) \exp \left(-H_{f} / W_{f} C_{f}\right) \\
\sigma \Delta P=k W_{f}^{\alpha}, \alpha=\rho / \rho_{o}
\end{gathered}
$$

Where $M_{m} C_{m}, T_{m}$ is the thermal mass and temperature of the duct, $W_{f}$ is the airflow rate through the duct, $C_{f}$ is the specific heat of air, $T_{i}, T_{o}$ are the inlet and outlet air temperature. $H_{f}, Q_{f}$ are the heat transfer coefficient and the heat transfered between air and the duct. $H_{a}, Q_{a}$ are the heat transfer coefficient and the heat transfered between ambient and the duct. $\Delta P$ is the pressure loss of the duct, and $\rho, \rho_{o}$ are air density in specific state and standard atmospheric density.

\subsection{Heat Exchanger Model}

Heat exchanger is cross flow type and assumed to be made of stainless steel. The hot side and cold side pressure drop are modeled according to equation (9). Subcell lumped parameter model is used for the modeling of temperature dynamic using equation (10), (11), (12). 
More detailed information can be found from reference [7-9]

$$
\begin{aligned}
& r_{h} \rho_{h} C_{h}\left(\partial T_{h} / \partial t\right)+W_{h} C_{h}\left(\partial T_{h} / \partial x\right)=H_{h}\left(T_{m^{-}} T_{h}\right) \\
& r_{c} \rho_{c} C_{c}\left(\partial T_{c} \partial \partial t\right)+W_{c} C_{c}\left(\partial T_{c} \partial y\right)=H_{c}\left(T_{m^{-}} T_{c}\right) \\
& M_{m} C_{m}\left(\partial T_{m} / \partial t\right)-H_{h}\left(T_{h^{-}} T_{m}\right)-H_{c}\left(T_{c^{-}} T_{m}\right)=0
\end{aligned}
$$

Where $W_{h}, W_{c}$ are the hot side and cold side flow rate. $H_{h}, H_{c}$ are hot side and cold side heat transfer rate. $H_{h}, H_{c}$ are the specific heat of hot side and cold side air. $T_{m}, T_{h}$, $T_{c}$ are temperature of the heat exchanger core, hot side and cold side. $x, y$ are independent spatial variables and $t$ is the time variable. $\rho_{h}, \rho_{c}$ are air density of hot side and cold side.

\section{Simulation and Analysis}

\subsection{Control Operating Mode}

As shown in Figure 2, the compressed air is heated by the heater, and the outlet temperature can be controlled to reach a set value. The heated hot air is then divided into two air paths. One of the path is cooled by the heat exchanger and mixed with the other path, the outlet temperature can be controlled through the cooperation adjustment of the control valve 1 and control valve 2 .

Considering the heat capacity and volume effect of the pipeline/heat exchanger and high-pressurized air, the mixing temperature control is preferred to use a cascade control channel as shown in Figure 4[10]. As for the heater temperature, bang-bang control techniques are applied to perform the heater outlet temperature control.

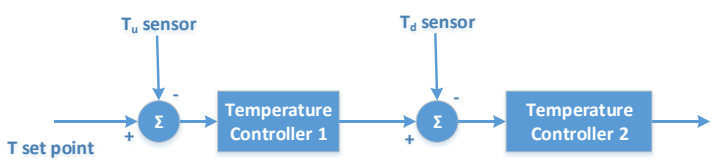

Figure 4. Temperature control configuration diagram

At the outlet of the EBATF, outflow valve 1 and outflow valve 2 are used to control the outlet air flow, which realize the pressure control. According to the pressure control requirement, electro-pneumatic control valves with the time constant less than 1s are preferred.

In summary, the entire EBATF has a total of six control channels plus a flow control channel to achieve system control. The flow control channel ensures minimum airflow through the heater and is to set a low limit in the case of warming up the system is necessary.

For this analysis, the control performance has not been optimized and the prime concern is to achieve stable operation. The control structure should be quite representative of what may actually be required for controlling the facility. It is set up so as to illustrate the dynamic performance of the system closed loop behavior only.

\subsection{Analysis of The Heater Control}

The controller uses bang-bang control techniques since the heating electrical power can only be full on or full off. Figure 5 shows the heater outlet temperature response using bang-bang control. The heater outlet temperature drops in about $3 \mathrm{sec}$ during $\mathrm{T}_{\mathrm{d}}$ (mixing outlet temperature) rises, causing a surge of airflow through the heater. And it takes longer to warm up the heater to restore the maximun temperature due to the long heater time constant. Therefore it might be necessary to keep the heater temperature at its maximum for all operating conditions to meet all airflow surge demands.

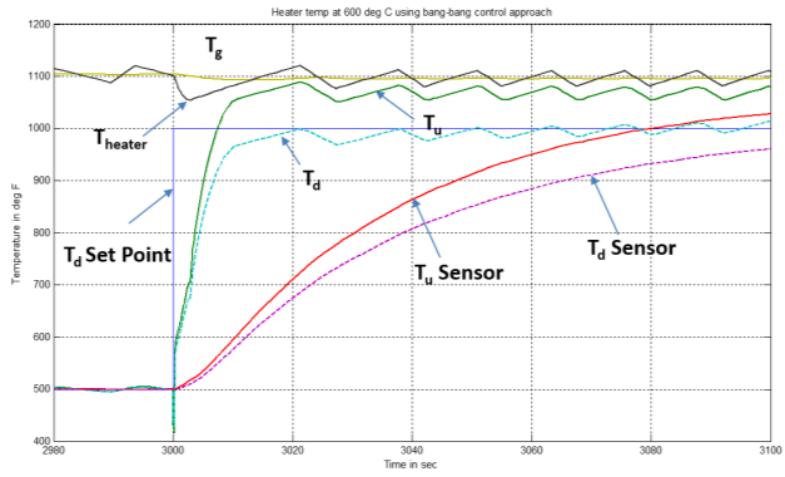

Figure 5. The heater outlet temperature response in ${ }^{\circ} \mathrm{F}$ using bang-bang control

\subsection{Analysis of Temperature and Pressure Control}

The cascade control techniques are used during the mixing outlet temperature control to overcome the heat capacity and volume effect of the pipeline and the heat exchanger, as well as the high-pressurized air. Figure 6 shows that the mixing outlet temperature $\left(T_{u}\right)$ changes rapidly as the set point changes between different states. Comparing Figure 6 with Figure 7, the temperature control is stable and has no severe interactions with the pressure control, showing the facility structure mechanically decouples the temperature and pressure controls.

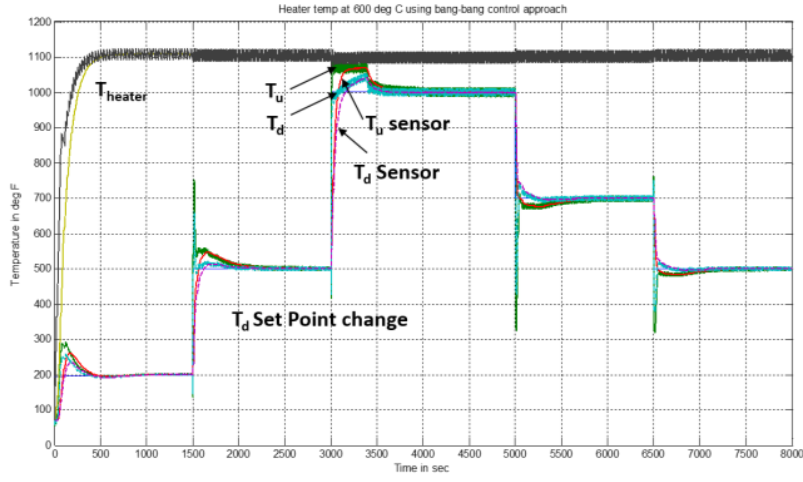

Figure 6. The mixing outlet temperature response in ${ }^{\circ} \mathrm{F}$ using cascade control.

As shown in Figure 7, the pressure control is stable and the response is rapid and accurate. 


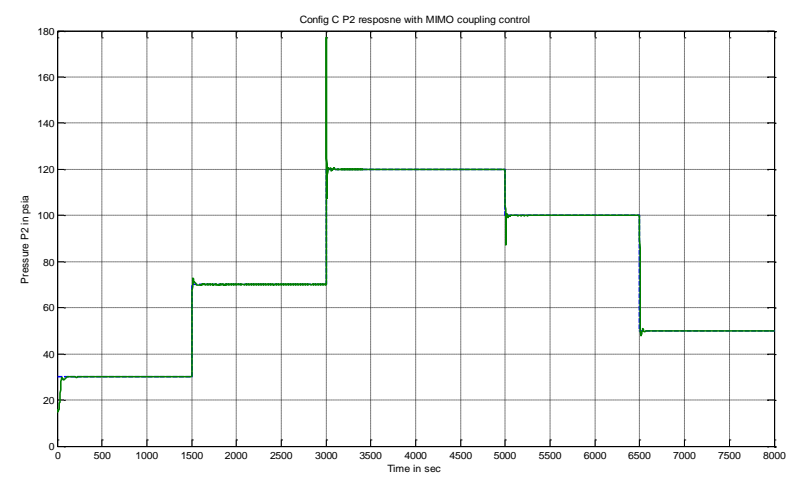

Figure 7. The pressure response in psia.

According to Figure 5, the mixing outlet temperature settling time is approximately 18 seconds, which cannot meet the dynamic requirement. Raise the temperature set point of the heater to $700{ }^{\circ} \mathrm{C}$ and get the temperature response as shown in Figure 8. The temperature settling time is approximately 8 seconds, meets the requirement. Therefore, a heater with higher temperature output should be used whenever physically possible.

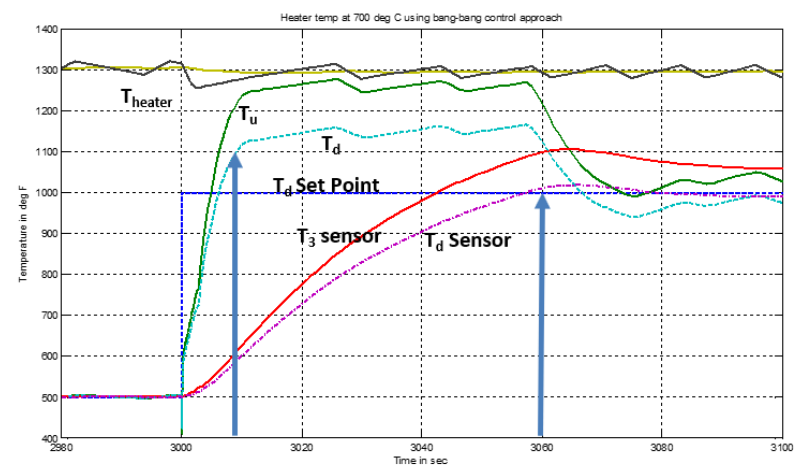

Figure 8. The temperature response after raising the heater outlet temperature.

\section{Conclusion}

For the purpose to perform the control design of Engine Bleed Air Test Facility, a dynamic simulation model for the facility was developed to simulate the dynamic behaviour. Common equipment performance is chosen to reflect the real system state to the greatest extent. Detailed modeling approaches have been introduced within several main equipments of EBATF. This simplified dynamic model may be used to perform trade studies and to optimize component characteristics for performance and cost comparison purposes.

Different control techniques are used to evaluate the dynamic performance and to find the best control design method.

The pressure control performance is close to ideal and likely could emulate the engine dyanmic performance closely. The mixing outlet temperature control is also close to ideal when the heater outlet temperature raises up to $700{ }^{\circ} \mathrm{C}$. Bang-bang control produces limit cycling and has little effects upon the overall control performance and stability of the system.

With the performance shown, this Engine Bleed Air Test Facility should be quite capable to emulate the engine for bleed air system testing and evaluation.

\section{References}

1. SAE ARP 217D: Testing of Airplane Installed Environmental Control Systems. Warrendale, PA : Society of Automotive Engineers, (1999) .

2. J. HE, J. ZHAO. Dynamic Simulation of the Aircraft Environ-mental Control System. Chinese Journal of Aeronautics, Vol.14, No. 3, 129-133 (2001)

3. G. Fang, Z. Yao, Y. Hu. Modeling and Simulation for Temperature Control System of Environmental Control System Function Test. Machine Design and Research, 4, 82-85 (2012).

4. D. SCHOLZ, C. MÜLlER, T. GIESE, C. ERDMANN. FLECS: Functional Library of the Environmental Control System-A Simulation Tool for the Support of Industrial Processes. Proceedings of the 1st International Workshop on Aircraft System Technologies. 143-157 (2007)

5. B. Andersen. The Analysis and Design of Pneumatic Systems. R.E.Krieger Publishing Co. (1967).

6. L. Zalmanson. Components for Pneumatics Control Instruments. Pergamon Press. (1965).

7. P. Hodal and G. Liu, Bleed Air Temperature Regulation System: Modeling, Control, and Simulation, Proceedings of the 2005 IEEE International Conference on Control Applications, Toronto, Canada, 1003-1008 (2005)

8. J. Mason. Heat Transfer in Cross Flow. II Proceedings 2nd US National Congress of Applied Mechanics. New York: ASME, 801-803(1995)

9. W. Roetzel and Y. Xuan. The Dynamic Behaviour of Heat Exchangers, WIT Press, (1998).

10. T. Marlin. Process Control. McGraw Hill. (1995). 